\title{
Shortest Known Prion Protein Allele in Highly BSE-Susceptible Lemurs
}

\section{Sabine Gilch, Christian Spielhaupter and Her- mann M. Schätz|*}

Genecenter Munich, Max von Pettenkofer-Institute for Virology, Ludwig-Maximilians-University of Munich, Feodor-Lynen-Str. 25, D-81377 Munich, Germany

*Corresponding author

\begin{abstract}
We describe the shortest prion protein allele known to date. Surprisingly, it is found as a polymorphism exactly in a species (prosimian lemurs) which seems highly susceptible to oral infection with BSE-derived prions. The truncation of the prion protein we found raises several questions. First, is the truncated octarepeat structure we describe, consisting of two octarepeats, still functional in copper binding? A second question is whether this truncation is related to the remarkable oral infectibility of lemurs with BSE-derived prions. And finally, one could argue that this genotype alone might favour development of a prion disease, even in the absence of exogenous infection.

Key words: BSE / Lemur / Octarepeats / Prion /

Prosimians / PrP allele.
\end{abstract}

Prion diseases such as kuru, bovine spongiform encephalopathy (BSE) and the new variant of CreutzfeldtJakob disease (nvCJD) represent prion disorders acquired by exogenous infection (Prusiner, 1997). Nonhuman primates have been extensively used for the study of prion infectivity until transgenic mouse models became available (Brown et al., 1994). Nevertheless, non-human primate models are considered extremely valuable for studying prion disease pathogenesis because they represent the experimental model closest related to the situation in human beings. Recently, both natural and experimental oral infection of lemur monkeys by BSE-derived prions was reported (Bons et al., 1999). The pathologic prion protein $\left(\mathrm{PrP}^{\mathrm{Sc}}\right)$ isoform could be detected in affected lemurs in lymphoid tissues and that of the peripheral and the central nervous system prior to the clinical onset of prion disease symptoms. Therefore, these prosimian monkeys might represent a very important experimental model for the study of prion pathogenesis and of tissue distribution of prion infectivity.

The knowledge of prion protein ( $\mathrm{Pr}$ ) primary structures has provided important insights into various putative structural and functional aspects of PrP and into species barrier mechanisms (Schätzl et al., 1995; Wopfner et al., 1999). Although the PrPs of more than 25 non-human primate species have been analyzed (Schätzl et al., 1995), no data for prion protein genes of prosimian species were available. Using PrP gene sequence analysis we addressed the question why lemur monkeys as prosimians represent such excellent hosts for oral BSE infection. For the preparation of genomic DNA we used peripheral blood leukocytes of a white ruffed lemur (Lemur/Varecia variegatus variegatus) and of a black lemur monkey (Lemur macaco albifrons; materials courtesly provided by the Zoological Gardens of San Francisco, USA). Using the degenerated primers FWA and FWH (Wopfner et al., 1999) we generated PCR products corresponding to amino acid residues 27 - 192 (human numbering system; GenBank accession number AF 177293). From agarose gel analysis it was evident that the lemurs we have analyzed might be heterozygous, carrying two alleles of different size (Figure 1). We sequenced both alleles directly from PCR products and upon subcloning of individual clones into suitable vectors. A comparison with known PrP sequences demonstrated that the generated PrP sequence was a unique and novel PrP sequence and that we have identified a PrP polymorphism in heterozygous animals. The lemur PrPs we have analyzed encoded methionine at codon 129 and did not encode the linear epitope mapped for the monoclonal anti-PrP antibody 3F4 (M KHM; residues 109-112)(Figure 2). Reactivity with this antibody was shown by Bons and colleagues in immunocytochemistry and immunoblotting

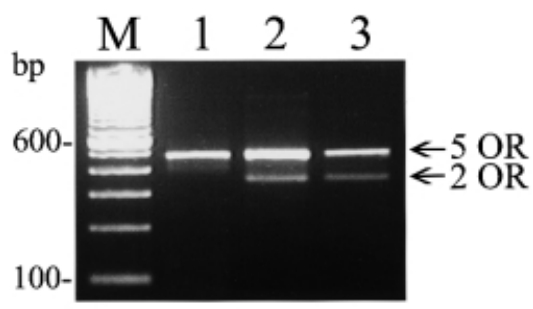

Fig. 1 PCR Analysis of LemurPrP Genes. Internal primers encompassing the octarepeat elements were used (LE3: AAC ACT GGG GGG AGC CGA TAC; LE4: CTT GAT GGT GAT ATT GAC GC). In lane $M$ a DNA size marker is shown (100 bp ladder). Lane 1 represents DNA amplified by PCR from human genomic DNA, lane 2 contains PCR products from genomic DNA of a black lemur, and lane 3 of a ruffed lemur. DNAs in lane 2 and 3 represent a PrP polymorphism in heterozygous animals. Depending on the PCR conditions one of the two alleles was more pronounced in intensity. 
Fig. 2 Alignment of Octarepeat Sequences of Various PrPs.

The deduced PrP amino acid sequences from residue 51 to 119 were aligned (numbering system related to human PrP; Schätzl et al., 1995; Wopfner et al., 1999). The lemur monkey was compared to cattle, sheep, goat, marmoset monkey (representing new-world monkeys), macaque (representing old-world monkeys), chimpanzee (representing great apes), and human. The octarepeat structure is indicated by stretches of 8 (9) amino acids interrupted by spaces. The number of octarepeats for a given PrP allele is indicated in brackets. Mammalian PrPs usually consist of 5 octarepeats; the bovine PrP can be heterozygous, having either 5 or 6 octarepeats. For goats the recently described polymorphic allele encoding 3 octarepeats is shown (Goldmann et al., 1998). The first two lines depict the polymorphism in lemurs with a short allele encoding two and a long allele encoding five octarepeats.

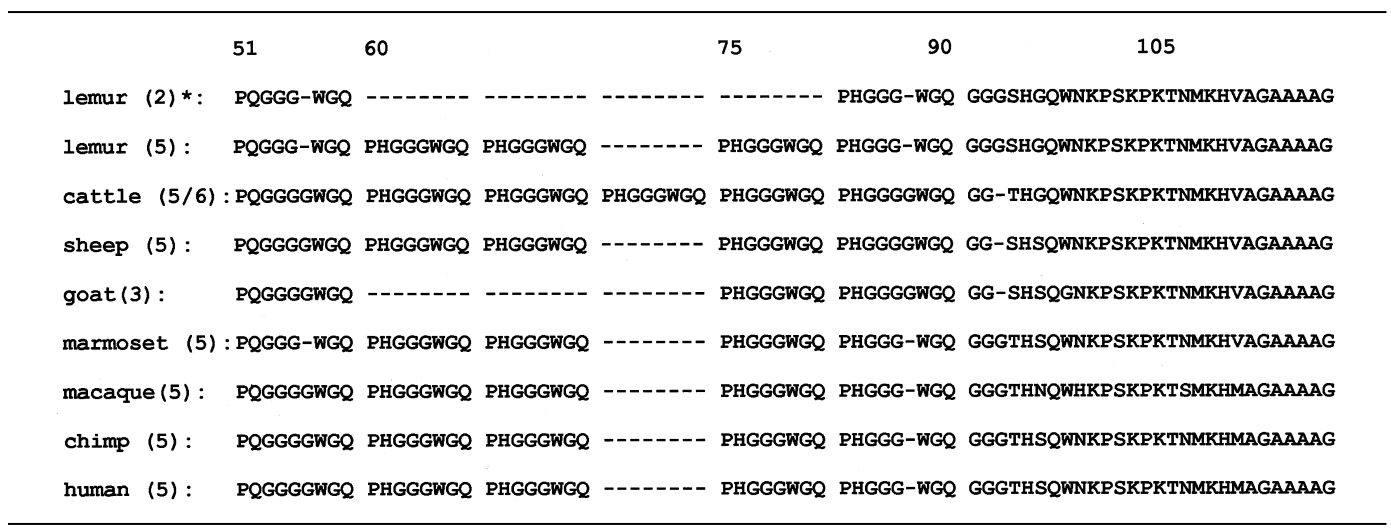

*: Number of octarepeats for a given allele in brackets; polymorphic alleles of lemur $(2 / 5)$, goat $(3 / 5)$ and cattle $(5 / 6)$ are shown.

experiments (Bons et al., 1999). Whether this might be explained by interspecies variability within various lemur subspecies has to be determined.

Mammalian PrPs have a characteristic repeat structure located at the $\mathrm{N}$-terminal part, usually consisting of a five time repetition of 8 (9) residues (octarepeat sequence PHGGGWGQ). Avian PrPs consist of 6 - 9 repeats of 6 residues (Wopfner et al., 1999), and a marsupial PrP consisting of 4 repeats of 9 - 10 residues was also described (Windl et al., 1995). Interestingly, the short lemur PrP allele showed the deletion of three entire octarepeats, yielding the shortest known PrP with only two octarepeats (Figure 2). The functional significance of the repeat structure is not entirely clear, but evidence is growing in support of a functional role of this element in copper binding (Hornshaw et al., 1995; Brown et al., 1997; Viles et al., 1999). Some minor inter- and intra-species variability within the repeat structure is known (Wopfner et al., 1999), and recently a goat $\mathrm{PrP}$ polymorphism was described with three octarepeats in one allele (Goldmann et al., 1998). Apparently, goats encoding three octarepeats showed an improved resistance against infection with caprine prions (Goldmann et al., 1998). Loss of one allele has no effect on prion disease susceptibility in humans and primates (Schätzl et al., 1995). On the other hand, the insertion of two and more octarepeats in human beings is clearly associated with familial Creutzfeldt-J akob disease (Owen et al., 1989; Palmer and Collinge, 1993). Interestingly, the presence of the $\mathrm{N}$-terminal part of $\operatorname{PrP}$ (i.e. residues 23 - 90) is dispensable for prion protein infectivity (Rogers et al., 1993; Fischer etal., 1996), although recent data suggest a role in modulating prion disease pathogenesis (Weissmann and Flechsig, personal communication).
Our finding that lemurs encode a truncated PrP allele raises several important questions. First, is the octarepeat structure, consisting of two octarepeats, still functional in copper binding? Recent data described the cooperative nature of PrP-copper complex formation and suggested a functional requirement for four octarepeats (Viles et al., 1999). In line with this one would predict that the lemur P rP with two octarepeats is significantly impaired in its biological function. A second aspect is whether this truncation is related to the remarkable oral infectibility of lemurs with BSE-derived prions. And finally, one could argue that this genotype alone might favour development of a prion disease, even in the absence of exogenous infection. Future animal studies are certainly needed to decipher the putative correlation between the P rP genotype described here and the outstanding oral susceptibility of lemurs to BSEderived prions.

\section{Acknowledgements}

We greatly appreciate the cooperation of the Zoological Gardens at San Francisco. This work was supported in part by grants of the F.-Baur Foundation, Munich, Germany, the Volkswagen Foundation, Hannover, Germany, and the German Research Foundation.

\section{References}

Bons, N., Mestre-Frances, N., Belli, P., Cathala, F., Gajdusek, D.C., and Brown, P. (1999). Natural and experimental oral infection of nonhuman primates by bovine spongiform encephalopathy agents. Proc. Natl. Acad. Sci. USA 96, 4046 4051. 
Brown, D.R., Qin, K., Herms, J.W., Madlung, A., Manson, J ., Strome, R., Fraser, P.E., Kruck, T., von Bohlen, A., SchulzSchaeffer, W., Giese, A., Westaway, D., and Kretzschmar, H. (1997). The cellular prion protein binds copper in vivo. Nature 390, 684 - 697.

Brown, P., Gibbs J r., C.J ., Rodgers-J ohnson, P., Asher, D.M., Sulima, M.P., Bacote, A., Goldfarb, L.G., and Gajdusek, D.C. (1994). Human spongiform encephalopathy: the National Institutes of Health series of 300 cases of experimentally transmitted disease. Ann. Neurol. 35, 513 - 529.

Fischer, M., Rulicke, T., Raeber, A., Sailer, A., Moser, M., Oesch, B., Brandner, S., Aguzzi, A., and Weissmann, C. (1996). Prion protein (PrP) with amino-proximal deletions restoring susceptibility of PrP knockout mice to scrapie. EMBO J . 15, 1255 1264.

Goldmann, W., Chong, A., Foster, J., Hope, J ., and Hunter, N. (1998). The shortest known prion protein allele occurs in goats, has only three octapeptide repeats and is non-pathogenic J. Gen. Virol. 79, 3173 - 3176.

Hornshaw, M.P., McDermott, J .R., and Candy, J .M. (1995). Copper binding to the $\mathrm{N}$-terminal tandem repeat regions of mammalian and avian prion protein. Biochem. Biophys. Res. Commun. 207, $621-629$.

Owen, F., Poulter, M., Lofthouse, R., Collinge, J ., Crow, T.J ., Risby, D., Baker, H.F., Ridley, R.M., Hsiao, K., and Prusiner, S.B. (1989). Insertion in prion protein gene in familial CreutzfeldtJ akob disease. Lancet 1, 51 - 52.
Palmer, M.S., and Collinge, J. (1993). Mutations and polymorphisms in the prion protein gene. Hum. Mutat. 2, 168 - 173.

Prusiner, S.B. (1997). Prion diseases and the BSE crisis. Science 278, $245-251$.

Rogers, M., Yehiely, F., Scott, M., and Prusiner, S.B. (1993). Conversion of truncated and elongated prion proteins into the scrapie isoform in cultured cells. P roc. Natl. Acad. Sci. USA 90, $3182-3186$.

Schätzl, H., DaCosta, M., Taylor, L., Cohen, F., and Prusiner, S.B. (1995). Prion protein gene variation among primates. J. Mol. Biol. 245, 362 - 374.

Viles, J.H., Cohen, F.E., Prusiner, S.B., Goodin, D.B., Wright, P.E., and Dyson, H.J . (1999). Copper binding to the prion protein: structural implications of four identical cooperative binding sites. Proc. Natl. Acad. Sci. USA 96, 2042 - 2047.

Windl, O., Dempster, M., Estibeiro, P., and Lathe, R. (1995). A candidate marsupial PrP gene reveals two domains conserved in mammalian PrP proteins. Gene 159, 181 - 186.

Wopfner, F., Weidenhöfer, G., Schneider, R., von Brunn, A., Gilch S., Schwarz, T.F., Werner, T., and Schätzl, H.M. (1999). Analysis of 27 mammalian and 9 avian PrPs reveals high conservation of flexible regions of the prion protein. J. Mol. Biol. 289, 1163 1178.

Received February 9, 2000; accepted April 5, 2000 